\title{
Esophageal rupture caused by compressed nitrous oxide
}

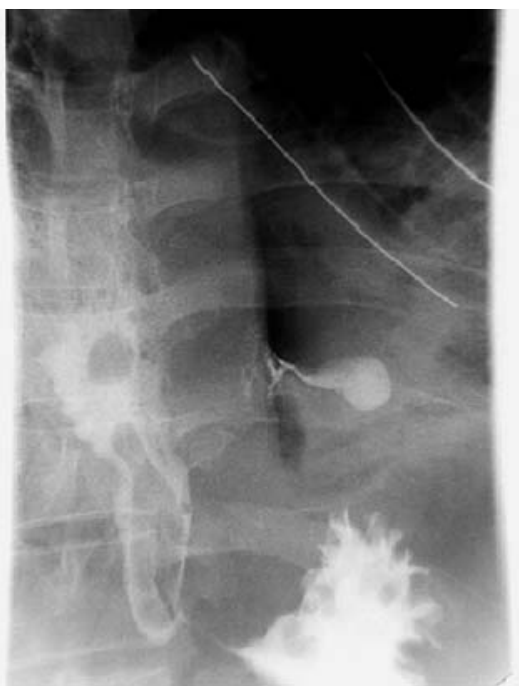

Fig. 1 Left lateral view of a Gastrografin swallow showing leakage of contrast from the lower third of the esophagus.

Rupture of the esophageal wall is most commonly iatrogenic. Boerhaave's syndrome refers to spontaneous esophageal perforation that occurs because of retching or vomiting. Spontaneous perforation of the esophagus results from a sudden increase in intraesophageal pressure combined with relatively a negative intrathoracic pressure. We report a case of esophageal rupture in a young patient caused by exposure to compressed nitrous oxide.

A 38-year-old man who worked for a company filling and transporting gas cylinders was brought to the emergency room with severe chest pain and shortness of breath. The patient reported that while opening a nitrous oxide cylinder, he had been exposed to a forceful jet of the nitrous oxide gas. His symptoms had started within minutes of this exposure. Physical examination revealed subcutaneous emphysema (crepitation) in his neck, and the absence of breath sounds on the left side of his chest. Chest radiography confirmed a pneumothorax and the patient had a chest drain inserted. A Gastrografin swallow was then performed, which revealed contrast leakage from the lower third of the esophagus ( $\bullet$ Fig. 1). A computed tomography (CT) scan of his chest showed thickening and edema of the left posteriolateral wall of the lower third of esophagus, air in the mediastinum, and a left-sided pleural effusion ( $\bullet$ Fig. 2 ).

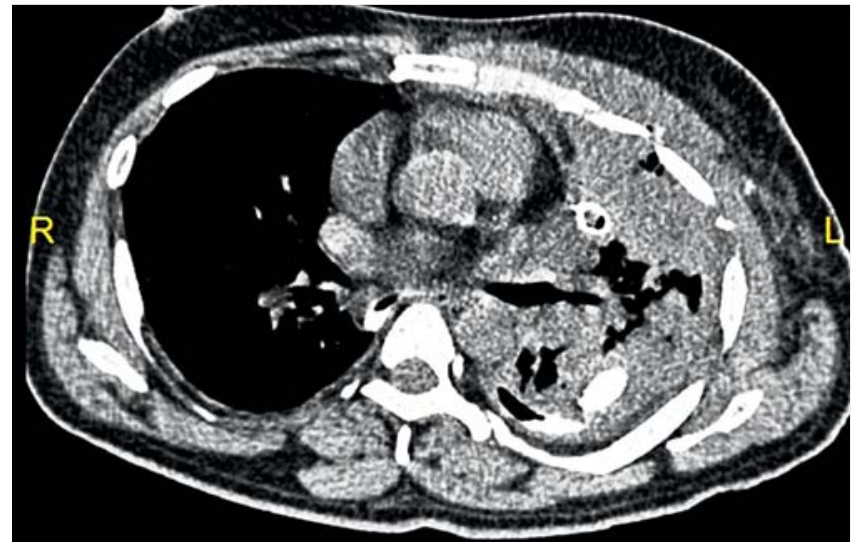

Fig. 2 Computed tomography (CT) scan showing air in the mediastinum, and a left-sided pleural effusion with a chest drain in position.

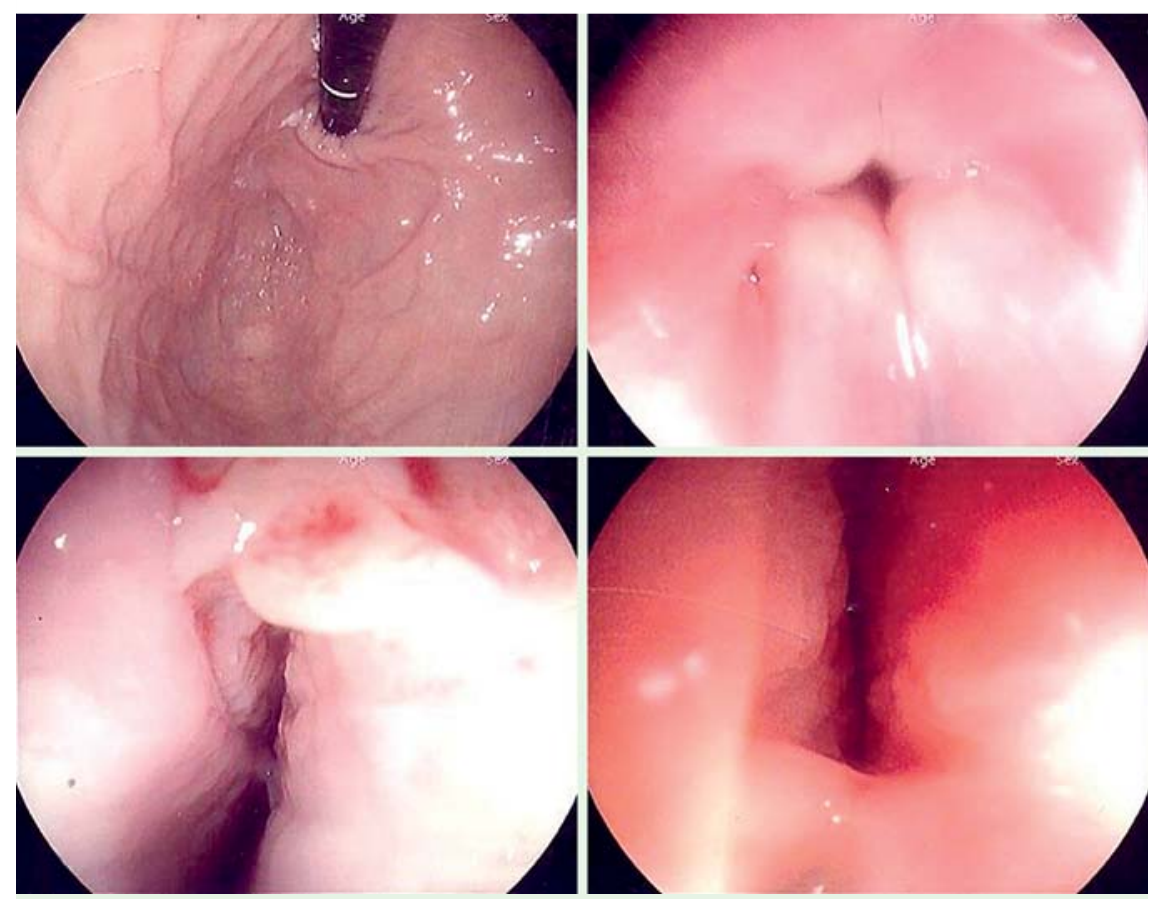

Fig. 3 Endoscopic views showing a tear in the esophageal wall.

Endoscopy revealed a tear in the esophagus at $35 \mathrm{~cm}$ from the incisors ( $\bullet$ Fig. 3). A fully covered self-expandable metal stent (SEMS) was deployed within 48 hours ( $\bullet$ Fig. 4). After the SEMS had been inserted, the drainage through the chest drain decreased significantly.

After 3 weeks, a methylene blue swallow was performed, which showed mild leakage of the dye into the chest drain. Endoscopy revealed partial migration of the stent and a second stent was deployed within the first one (telescopic stent). The methylene blue swallow was repeated 1 week later and did not show any further leakage, so both stents were removed. Repeat endoscopy a week later showed complete healing of the esophageal tear ( $\bullet$ Fig.5), and the patient was discharged home once he was tolerating oral feeding. Similar to previous cases $[1,2]$, in this case an esophageal tear occurred at the left posteriolateral aspect of the lower third of esophagus and extended for several centimeters. Here the cause of the rupture was an increase in the intraluminal pressure of the esophagus due to sudden exposure to compressed nitrous oxide. Rupture of the esophagus has also been reported due to compressed air from burst- 


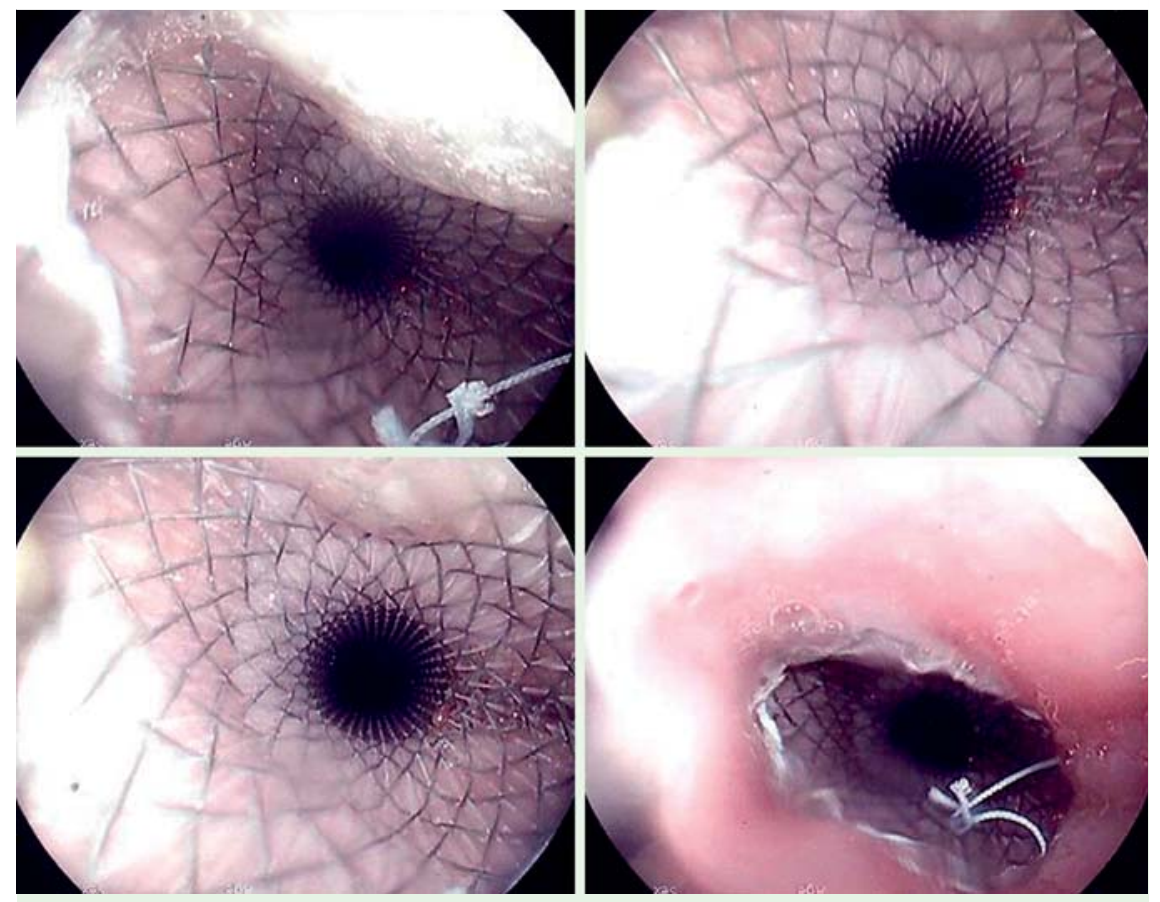

Fig. 4 The fully covered self-expandable metal stent (SEMS) positioned to cover the esophageal tear.

ing an automobile tire and from positive pressure ventilation [3-5].

Esophageal rupture has a high morbidity and mortality; early diagnosis and prompt management can save the patient's life.

Endoscopy_UCTN_Code_CCL_1AB_2AC_3AH

Competing interests: None
Rafie A. Yakoob, Nazeeh Al Dweik, Hamid Ullah Wani, Muneera Mohannadi, Saad Al Kaabi

Department of Medicine, Division of Gastroenterology, Hamad Medical Corporation, Doha, Qatar

\section{References}

1 Meyerovitch J, Ben Ami T, Rozenman J et al. Pneumatic rupture of the esophagus caused by carbonated drinks. Pediatr Radiol 1988; 18: $468-470$

2 Yu Y, Ding S, Zheng Y et al. Esophageal rupture caused by explosion of an automobile tire tube: a case report. J Med Case Rep 2013; 7: 211

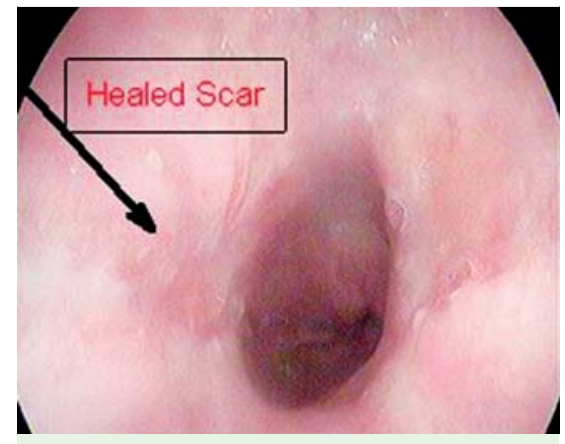

Fig. 5 Endoscopy 1 week after the insertion of a second self-expandable metal stent (SEMS) showing that the esophageal tear had healed.

3 Ozgüner IF, Savaş C, Yeşildağ A. An unusual type of severe barotrauma owing to automobile tire biting in a child. J Pediatr Surg 2004; 39: $1584-1585$

4 Gelfand ET, Fisk RL, Callaghan JC. Accidental pneumatic rupture of the esophagus. J Thorac Cardiovasc Surg 1977; 74: 142 - 144

5 Schweigert $M$, Beattie R, Solymosi $N$ et al. Endoscopic stent insertion versus primary operative management for spontaneous rupture of the esophagus (Boerhaave syndrome): an international study comparing the outcome. Am Surg 2013; 79: 634-640

\section{Bibliography}

Dol http://dx.doi.org/

10.1055/s-0034-1365437

Endoscopy 2015; 47: E189-E190

(c) Georg Thieme Verlag KG

Stuttgart · New York

ISSN 0013-726X

\section{Corresponding author}

\section{Hamid Ullah Wani, MD}

Department of Medicine

Division of Gastroenterology

Hamad Medical Corporation

Doha, 3050

Qatar

drhamidwani@gmail.com 